\title{
Characterization of geo-electrical properties to delineate groundwater potential in part of Deccan Volcanic Province of India

\author{
SYED SHAMS AHMAD RIZVI
}

Central University of Karnataka

Presenting Author: shamsrizviamu@gmail.com

An attempt has been made to explore the aquifer potentiality through the vertical electrical sounding survey in a part of the Deccan volcanic province of India, to provide the water potential zones, in the light of water security and their development and management for future use. In this concern, thirty six vertical electrical sounding surveys were conducted using a resistivity meter, covering the entire study region in a systematic manner. Schlumberger configuration was followed during the entire survey. A preliminary investigation was taken into the region to select and make the plan for a suitable site spot for the different locations. Four winches, five probes, two hammers, and two measuring tapes were used during the survey. A GPS was used to record the latitude, longitude and, elevation at different locations. Geologically, the study region is bounded by Deccan traps (basalts) with intertrappean beds at some places. Different types of curves were identified during the survey in which three, four, and five-layered curves were common. These curves include A, $\mathrm{K}, \mathrm{H}, \mathrm{HA}, \mathrm{KH}, \mathrm{AK}, \mathrm{KHK}$, and HKH. Geo-electrical profile sections have been prepared and analyzed. The two-dimensional (2-D) representations of pseudo-cross sections and resistivity cross-sections were created using the interpolation of the subsurface apparent resistivity variation. The three-dimensional (3D) sub-surface maps of different resistivity layers were prepared for a better interpretation. On the basis of the resistivity and thickness layers, shallow well and bore well have been recommended at some places within the study region. 